\title{
Laboreal
}

Volume $11 \mathrm{~N}^{\circ} 1$ | 2015

Modos de vida e trabalho

\section{Gestão em saúde, uma perspectiva ergológica: com quantos gestos se faz uma gestão}

Gestión de la salud, una perspectiva "ergológica": cuántos gestos caracterizan una gestión

Gestion dans le domaine de la santé, une perspective ergologique: combien de gestes font une gestion

Health management, an ergological perspective: how many gestures to make a management

\section{Wladimir Ferreira de Souza}

\section{OpenEdition}

\section{Journals}

Edição electrónica

URL: http://journals.openedition.org/laboreal/4401

DOI: $10.4000 /$ laboreal. 4401

ISSN: 1646-5237

\section{Editora}

Universidade do Porto

\section{Refêrencia eletrónica}

Wladimir Ferreira de Souza, « Gestão em saúde, uma perspectiva ergológica: com quantos gestos se faz uma gestão », Laboreal [Online], Volume $11 N^{0} 1$ | 2015, posto online no dia 01 julho 2015, consultado o 24 setembro 2020. URL : http://journals.openedition.org/laboreal/4401 ; DOI : https:// doi.org/10.4000/laboreal.4401

Este documento foi criado de forma automática no dia 24 setembro 2020.

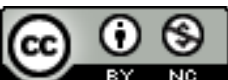

Laboreal está licenciado com uma Licença Creative Commons - Atribuição-NãoComercial 4.0 Internacional. 


\section{Gestão em saúde, uma perspectiva ergológica: com quantos gestos se faz uma gestão}

Gestión de la salud, una perspectiva "ergológica": cuántos gestos caracterizan una gestión

Gestion dans le domaine de la santé, une perspective ergologique: combien de gestes font une gestion

Health management, an ergological perspective: how many gestures to make a management

Wladimir Ferreira de Souza

\section{REFERÊNCIA}

Souza, W. F. (2009). Gestão em saúde, uma perspectiva ergológica: com quantos gestos se faz uma gestão. Tese de Doutoramento em Psicologia Social, Instituto de Psicologia, Universidade do Estado do Rio de Janeiro, Rio de Janeiro.

\section{NOTA DO EDITOR}

http://dx.doi.org/10.15667/laborealxi0115wfs

Manuscrito recebido em: novembro/2014

Aceite após peritagem: abril/2015 


\section{Introdução}

1 Na tese de doutoramento aqui apresentada analisou-se uma experiência concreta de gerenciamento em uma organização da rede pública de saúde no Brasil, orientada pela démarche ergológica. A tese (Souza, 2009) originou-se da pesquisa-intervenção realizada de 2005 a 2008 em um Centro Municipal de Saúde (CMS), localizado em um município do estado do Rio de Janeiro. A discussão principal deu-se em torno da análise de uma modalidade gestionária, denominada ergogerenciamento (Souza \& Athayde, 2011) tradução livre do francês l'ergomanagement (Schwartz \& Prévot-Carpentier, 2007). Entende-se que aí se compreende e se opera o que a ergologia (Schwartz, 2000; 2010a) denomina gestão das gestões, tendo como operador transversal o ponto de vista da atividade (Guérin, Laville, Daniellou, Duraffourg \& Kerguelen, 2001).

2 Havia uma peculiaridade naquele lócus de intervenção e análise: o pesquisador, autor da tese, era também o diretor geral da unidade de saúde. Desse modo, a pesquisa empreendeu-se conjuntamente com a experiência concreta de gerenciamento, o que permitiu trazer à tona diversas questões. Essas questões foram exaustivamente debatidas nas reuniões do grupo de pesquisa; nos encontros com os trabalhadores, e também durante o estágio doutoral realizado em 2007 com financiamento da CAPES na Universidade de Aix-Marseille, sob a orientação de Yves Schwartz.

Entendeu-se que mantido o rigor teórico e metodológico, o desempenho da atividade de modo híbrido (o pesquisador sendo também o diretor) poderia ser extremamente favorável, tanto para o aprofundamento da pesquisa-intervenção, quanto para o encaminhamento mais resolutivo das problemáticas atinentes àquele local. Apostava-se ainda no profícuo desenvolvimento de uma experiência que se propunha seguir as vias possíveis para um ergogerenciamento.

4 Buscou-se explorar, no curso da própria atividade de gerenciamento, pistas que apontassem em que medida uma perspectiva gestionária - uma gerência ergológica (ou ergogerenciamento) orientada pela e para a atividade de trabalho - contribuiria para afirmar a potência de agir dos coletivos e poderia trazer à tona algumas das reservas de alternativas presentes naquela unidade de saúde.

5 Algumas conquistas puderam ser vislumbradas em decorrência da experiência de gerenciamento no CMS, como o incremento do interesse, envolvimento e participação efetiva dos trabalhadores no processo de construção e manutenção de um espaço de debate e deliberação coletiva, os Encontros sobre o Trabalho - EST (Durrive, 2010). Estes decorreram de uma primeira tentativa de organização dos próprios trabalhadores de um Grupo de Trabalho de Humanização (GTH), que tinha como objetivo realizar debates e deliberações sobre a humanização da atenção e da gestão, conforme proposto na Política Nacional de Humanização do Ministério da Saúde do Brasil.

6 Embora o CMS constitua-se como uma unidade que goza de referências positivas no que tange ao atendimento na localidade, essa primeira tentativa de discussão centrada na "humanização" apresentou limites, advindo no grupo uma demanda de análise ampliada, incorporando aspectos referentes à organização e às condições de trabalho. A partir dessa demanda o diretor propôs e foi aceita a participação dos pesquisadores nas reuniões seguintes, que se constituíram como EST.

7 Avalia-se que esse movimento desde o GTH até a sua culminância com os EST teve repercussões na melhoria de algumas condições de trabalho, de saúde e segurança dos 
trabalhadores e em modificações positivas no funcionamento da unidade de saúde, manifestamente reconhecidas nas conversas e encontros com os trabalhadores, nas reuniões com clientes/usuários dos serviços e com a hierarquia (representantes da Secretaria Municipal de Saúde).

\section{Referenciais teóricos}

8 O prefixo Ergon (do grego) destaca a relevância da atividade, categoria central para a análise do trabalho em ergologia e em ergonomia da atividade.

9 A ergologia (Schwartz, 2000; 2010a) pode ser entendida como uma postura, uma forma de pensar a atividade humana que nos ajuda a entender que trabalhar é pensar, trabalhar é gerir a atividade, as dramáticas de uso do corpo-si (do ser humano em sua integralidade). Contribui também para que se intervenha de forma cuidadosa (com rigor, método e afeto) nas situações de trabalho. A démarche (perspectiva) ergológica pode ser compreendida como um rastreamento das situações reais de atividade humana, onde as pessoas vivem e trabalham. "Ir ao encontro" das atividades humanas, especialmente das atividades de trabalho.

10 A influência da ergonomia da atividade (Guérin et al., 2001) - abordagem orientada para uma análise sistêmica da atividade humana no trabalho - deu-se ao longo de todo o processo de pesquisa-intervenção conduzindo a análise situada do trabalho. Encontrouse também uma importante fonte de inspiração na psicodinâmica do trabalho (Dejours, 1992; 1995; Dejours, Abdoucheli \& Jayet, 1994), a qual norteou a atenção para os recursos da inteligência da prática e para os sistemas defensivos mobilizados diante dos desafios que poderiam produzir sofrimento patogênico ou criativo.

11 Os contributos de outros autores permitiram discutir as possibilidades de estabelecerem-se naquele local relações não bancárias/depositárias de saberes e prescrições no outro (Freire, 1974), de lá construir-se um ambiente de trabalho "facilitador", possibilitador de suporte ("holding") (Winnicott, 1975) e tornar-se espaço "matrístico", matriz de desenvolvimentos (Maturana, 2004).

12 Explorou-se também o debate sobre o modelo da competência presente em Zarifian (2001).

\section{Metodologia}

13 Tendo o ponto de vista da atividade como operador transversal, a opção metodológica contemplou diferentes inspirações de métodos e técnicas das ciências do trabalho.

14 A pesquisa empírica encaminhou-se através do dispositivo que contempla conversas e Encontros sobre o Trabalho (EST), o que possibilitou confrontar alguns pontos de vista, alguns modos de trabalhar e de gerir, em busca da constituição do ponto de vista da atividade (Guérin et al., 2001).

15 Além dos encontros que foram se dando no cotidiano informal da pesquisa, foram realizados cinco EST, dos quais participaram profissionais do CMS de diferentes formações e níveis de escolaridade e os pesquisadores profissionais. Dentre os pesquisadores estavam o autor da tese, o professor-pesquisador orientador da tese, outro professor-pesquisador e um auxiliar de pesquisa, graduando em Psicologia. 

participação foi a adesão voluntária ao convite feito por cartazes ou pessoalmente, pelos pesquisadores ou por outros trabalhadores. O grupo não era fixo, podendo receber novos participantes a cada encontro.

\section{Discussão sobre as vias para um (ergo)gerenciamento}

17 Destaca-se o "chegar junto" (expressão popular no Brasil) como estratégia adotada pelo diretor-pesquisador. Esta remete ao dispositivo dinâmico de três polos - DD3P (Schwartz, 2000; 1996/2004) e suas exigências para a construção de um espaço dialógico e de confrontação de saberes. O primeiro polo refere-se aos conceitos, aos saberes sistematizados, organizados, formalizados nas diversas disciplinas. O segundo polo refere-se à atividade, aos saberes singulares gerados nas atividades. $O$ terceiro polo, das exigências éticas e epistêmicas é necessário para que se dê o encontro, o diálogo, o debate, a deliberação, o reconhecimento das zonas de cultura e incultura recíprocas que envolvem os dois outros polos.

18 A direção do CMS procurou assumir uma postura marcada pelo seu caráter situado e por uma configuração e uma confluência que possibilitam trabalhar junto, viver junto, "pensar junto", buscando compreender a atividade juntamente com aqueles (as) com quem se trabalha.

19 No entanto, foi preciso um longo período, marcado por aproximações e distanciamentos, por delegação e assunção de responsabilidades, estabelecimento de condições razoáveis de trabalho, atendimento de algumas reivindicações mais contundentes (relacionadas às necessidades mais prementes), para que fosse possível estabelecer autoridade, respeitabilidade e as condições favoráveis para construir o momento oportuno, as ocasiões em que o encontro com o coletivo dos trabalhadores e com os usuários pudesse ser demandado e viesse a acontecer.

Considera-se que os questionamentos com os quais se deparou o diretor nesses encontros agiram como poderosas forças de convocação de novos atores e de novos questionamentos, possibilitando outros férteis encaminhamentos, contribuindo para desenvolver e não para emperrar o movimento em vias de ergogerenciamento.

21 A disponibilidade para a confrontação de ideias, para o debate sinérgico, a busca de tornar aquele um ambiente facilitador e matrístico contribuiu para um encaminhamento mais fértil dos recursos da inteligência da prática (Dejours, 1995), para dar visibilidade a ingredientes da competência e a reservas de alternativas, a estratégias criativas para lidar com as dificuldades cotidianas, possibilitando encontrar a nobreza da atividade ali presente, o agir em competência (Schwartz, 1998; 2000; 2010b), o "assumir responsabilidades e tomar iniciativa" em situações de trabalho (Zarifian, 2001) em um espaço público de discussão/deliberação coletiva (Dejours, Abdoucheli \& Jayet, 1994).

Alguns casos citados a seguir demonstram esse movimento.

23

Sugeriu-se a um funcionário a sua transferência para o setor de almoxarifado, um setor que necessitava ser reorganizado. Ele aceitou de imediato e passou a utilizar os seus 
ingredientes da competência de modo bastante eficiente e eficaz, declarando-se bastante satisfeito com a mudança.

Porém, no início, essa mudança gerou algumas reclamações de outros funcionários, pois com ela passou a haver maior controle sobre a quantidade de materiais liberados. Posteriormente, nos EST chegou-se à conclusão de que o maior controle favorecia a todos, pois passaram a ter maior garantia de que receberiam os materiais de que precisavam, não havendo, mais a necessidade de fazerem pequenos estoques em cada setor, o que faziam por receio de lhes faltar material imprescindível às suas atividades.

Outra funcionária que atuava na recepção relatou que utilizava uma estratégia para lidar com usuários mais exaltados. Nas raras vezes em que não obtinha sucesso em acalmar a pessoa e conseguir ser ouvida, utilizava outra estratégia que envolvia o coletivo de trabalhadores do setor: sair de cena e convocar outro colega para assumir o atendimento.

Esses e outros relatos foram feitos durante os EST corroborando a hipótese de que contribuiriam para a troca de experiências, para o diálogo sobre a atividade e para a mudança de ponto de vista de alguns trabalhadores acerca daquele ambiente de trabalho.

Se nos primeiros EST o CMS foi ressaltado como sujo, feio, desconfortável, lentificante, no decorrer dos encontros emergiram outras de suas características, como a sua importância histórica no tratamento das questões da saúde da população e dos próprios trabalhadores, a qualificação da equipe, o diálogo e a proximidade com os usuários. Um espaço antes visto como imutável, adoecedor e que desvalorizava os profissionais teve, por meio dos encontros e conversas, sua potencialidade realçada pelos próprios trabalhadores e usuários, tornando-se então um espaço potencial e analítico.

\section{Considerações finais}

Nas experiências analisadas verificou-se a busca de um gerenciamento sensível às gestões desenvolvidas pelos trabalhadores no curso das ações situadas e ao ponto de vista dos usuários. Alguns procedimentos, que a princípio pareceriam óbvios, revelavam de fato uma aposta nas possibilidades de um encaminhamento conjunto e eficaz do trabalhar e do viver, procurando-se evitar que estes tomassem um rumo ineficaz, improdutivo, desagregador, adoecedor.

Destaca-se aqui que o debate em torno do ergogerenciamento aponta pistas importantes para o desenvolvimento do Sistema Único de Saúde no Brasil.

É necessário assumir os riscos e desafios nesse campo, pois, apesar de alguns possíveis dissabores, também há sabores a desfrutar, há o prazer de descobrir em cada situação singular um encaminhamento promissor para um trabalhar de outro modo, transformando e afirmando o trabalho na direção da saúde e da vitalidade dos humanos. 


\section{BIBLIOGRAFIA}

Dejours, C. (1992). A loucura do trabalho: estudo de psicopatologia do trabalho. 5. Ed. ampliada. São Paulo: Cortez-Oboré.

Dejours, C. (1995). Inteligência operária e organização do trabalho. A propósito do modelo japonês de produção. In H. Hirata (Org.). Sobre o modelo japonês (pp. 281-309). São Paulo: Edusp.

Dejours, C., Abdoucheli, E., \& Jayet, C. (1994). Psicodinâmica do trabalho: contribuições da escola dejouriana à análise da relação prazer, sofrimento e trabalho. São Paulo: Atlas.

Durrive, L. (2010). Pistas para o ergoformador animar os encontros sobre o trabalho. In Schwartz, Y. \& Durrive, L. (Orgs.). Trabalho e Ergologia. 2. Ed. (pp. 309-318). (Coord. da trad. e rev. técnica J. Brito \& M. Athayde). Niterói: Editora da UFF.

Freire, P. (1974). Pedagogia do oprimido. Rio de Janeiro: Paz e Terra.

Guérin F., Laville, A., Daniellou, F., Duraffourg, J., \& Kerguelen, A. (2001). Compreender o trabalho para transformá-lo. A prática da Ergonomia. São Paulo: Edgard Blücher.

Maturana, H. R. (2004). Amar e brincar: fundamentos esquecidos do humano. São Paulo: Palas Atenas. Schwartz, Y (1996/2004). Ergonomia, filosofia e exterritorialidade. In F. Daniellou (Coord.). A ergonomia em busca de seus princípios: debates epistemológicos (pp. 141-180). São Paulo: Edgard Blücher.

Schwartz, Y. (1998). Os ingredientes da competência: um exercício necessário para uma questão insolúvel. Educação e Sociedade, 19, 65. Retirado março, 15, 2007 de www.scielo.br/scielo.php? pid=S0101-73301998000400004\&script=sci_arttext.

Schwartz, Y. (2000). Le paradigme ergologique ou un métier de Philosophe. Toulouse: Octarès. Schwartz, Y. (2010a). Trabalho e Ergologia. In Y. Schwartz \& L. Durrive (Orgs.). Trabalho e Ergologia: conversas sobre a atividade humana. 2. ${ }^{a}$ Ed. rev. e ampliada (pp. 25-46). Niterói/RJ: EdUFF. Schwartz, Y. (2010b). Uso de si e competência. In Y. Schwartz, \& L. Durrive (Orgs.). Trabalho e Ergologia: conversas sobre a atividade humana. 2. ${ }^{\text {a }}$ Ed. rev. e ampliada (pp. 205-221). Niterói/RJ: EdUFF.

Schwartz, Y., \& Prévot-Carpentier, M. (2007). L'Ergomanagement. Retirado dezembro, 20, 2007, de www.arianesud.com.

Souza, W. F. (2009). Gestão em saúde, uma perspectiva ergológica: com quantos gestos se faz uma gestão. Tese de Doutoramento em Psicologia Social, Instituto de Psicologia, Universidade do Estado do Rio de Janeiro, Rio de Janeiro.

Souza, W. F., \& Athayde, M. (2011). Com quantos gestos se faz uma gestão em saúde? Tempus Actas de Saúde Coletiva, 5, 135-157.

Winnicott, D. (1975). o brincar e a realidade. Rio de Janeiro: Imago.

Zarifian, P. (2001). Objetivo Competência: por uma nova lógica. São Paulo: Atlas. 


\section{AUTOR}

\section{WLADIMIR FERREIRA DE SOUZA}

Universidade do Estado do Rio de Janeiro (UERJ), Instituto de Psicologia Departamento de Psicologia Social e Institucional, Rua São Francisco Xavier, 524 - 10ํandar - Sala 10.006, bloco B, Maracanã - Rio de Janeiro - RJ, Brasil, CEP: 20550-013

souzalandi@uol.com.br 